Terbit online pada laman web jurnal : http://jurnal.iaii.or.id

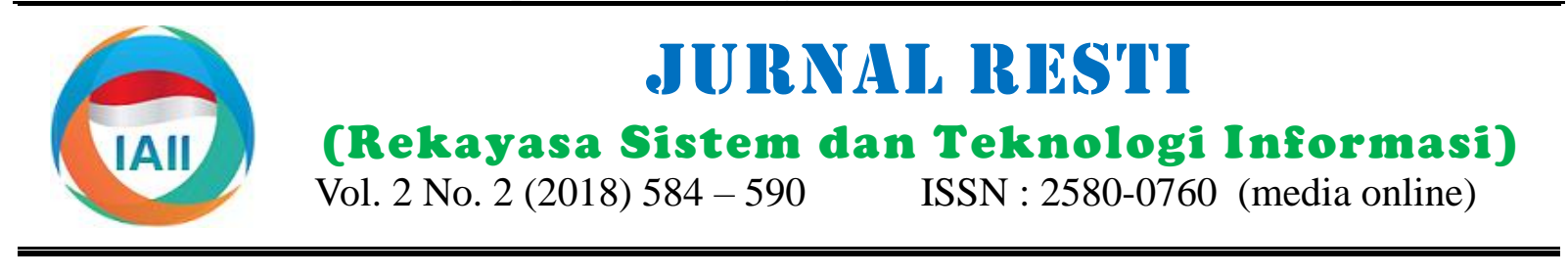

\title{
Penerapan Algoritma C4.5 Untuk Memprediksi Besarnya Penggunaan Listrik Rumah Tangga di Kota Batam
}

\author{
Yulia $^{\mathrm{a}}$, Nurul Azwanti ${ }^{\mathrm{b}}$ \\ ${ }^{a}$ Universitas Putera Batam, Fakultas Teknik dan Komputer, Teknik Informatika, yulia_edwar@yahoo.com \\ ${ }^{\mathrm{b}}$ Universitas Putera Batam, Fakultas Teknik dan Komputer, Sistem Informasi, nurulazw@ rocketmail.com
}

\begin{abstract}
Electricity has been proven from the activities carried out by everyday people. The use of electricity ranging from household appliances such as refrigerator, fan, iron, mixer, rice cooker to communication tools such as mobile phones, laptops and various other electronic devices desperately need electrical energy. The use of electricity today is the only thing that matters in people's lives. Batam is one of the major cities in Indonesia. The densely populated areas in Batam are the Batam Center area. Population density will also require electrical energy to be very high. Company as energy provider in Batam city is PT PLN Batam (b'right). If the population is not wise in using electricity, of course, will greatly affect the depletion of energy preparation lstrik in Batam City itself. Therefore, techniques are needed to make predictions in the use of household appliances for the purpose of the government in list listing program. Techniques in making predictions can use data mining techniques by classifying data using C4.5 algorithm. Results from calculation Algorithm C4.5 Formation of decision tree where variable number of family members, Building area and length of time at home. Testing done with Weka has produced the same rule from the result tree that formed.
\end{abstract}

Keywords: algorithm C4.5, prediction use of electricity, decision tree

\begin{abstract}
Abstrak
Listrik telah menjadi kebutuhan yang tidak terlepas dari kegiatan yang dilakukan oleh manusia sehari-hari. Penggunaan listrik mulai dari peralatan rumah tangga seperti kulkas, kipas angin, setrika, mixer, rice cooker hingga alat komunikasi seperti handphone, laptop dan berbagai macam alat eletronik lainnya sangat membutuhkan adanya energi listrik. Penggunaan tenaga listrik sekarang ini merupakan salah satu kebutuhan penting dalam kehidupan masyarakat. Batam merupakan salah satu kota besar yang ada di Indonesia. Daerah yang termasuk padat penduduk di Batam adalah daerah Batam Center. Kepadatan penduduk tersebut juga menyebabkan kebutuhan akan energi listrik menjadi sangat tinggi. Perusahaan sebagai penyedia sumber energi listrik di kota Batam adalah PT PLN Batam (b'right). Jika penduduk tidak bijak dalam menggunakan listrik, tentu saja akan sangat mempengaruhi menipisnya persediaan energi lstrik di Kota Batam itu sendiri. Untuk itu diperlukan suatu teknik untuk melakukan prediksi dalam penggunaan listrik rumah tangga agar tujuan dari pemerintah dalam upaya menerapkan program penghematan listrk tercapai. Teknik dalam melakukan prediksi dapat menggunakan teknik data mining dengan melakukan klasifikasi data dengan menggunakan Algoritma C4.5. Hasil dari perhitungan Algoritma C4.5 membentuk pohon keputusan dimana variabel jumlah anggota keluarga, luas bangunan rumah dan lama waktu di rumah menjadi variabel penting dari prediksi besarnya pengggunaan listrik. Pengujian dilakukan dengan Weka telah menghasilkan rule yang sama dari pohon keputusan yang terbentuk.
\end{abstract}

Kata kunci: algoritma C4.5, prediksi, penggunaan listrik, pohon keputusan

(C) 2018Jurnal RESTI

\section{Pendahuluan}

Listrik telah menjadi kebutuhan yang tidak terlepas dari kegiatan yang dilakukan oleh manusia sehari-hari. Peranan listrik tidak hanya menjadi kebutuhan sekunder, namun telah beralih menjadi kebutuhan primer dikarenakan tanpa adanya listrik segala kegiatan yang dilakukan akan sangat menghambat. Mulai dari peralatan rumah tangga seperti kulkas, kipas angin, setrika, mixer, rice cooker hingga alat komunikasi seperti handphone, laptop dan berbagai macam alat eletronik lainnya sangat membutuhkan adanya energi listrik. Pengunaan tenaga listrik sekarang ini merupakan salah satu kebutuhan penting dalam kehidupan masyarakat dan seringkali dianggap sebagai salah satu tolak ukur taraf kesejahteraan masyarakat seiring dengan perkembangan teknologi [1]. Semakin

Diterima Redaksi : 23-07-2018 | Selesai Revisi : 06-08-2018 | Diterbitkan Online : 10-08-2018 
banyak penggunaan listrik, maka semakin banyak pula prediksi yang akan diterapkan pada prediksi energi listrik yang dibutuhkan.

penggunaan listrik rumah tangga.

Batam merupakan kawasan yang saat ini memiliki jumlah penduduk yang sangat padat. Berdasarkan data Badan Pusat Statistik Kepulauan Riau pada tahun 2016 jumlah penduduk di Kota Batam mencapai 1.236.399 jiwa yang tersebar di berbagai daerah di Kota Batam. Salah satu daerah yang termasuk padat penduduk ialah daerah Batam Center. Wilayah Batam Center termasuk wilayah pusat kota Batam karena wilayah tersebut dekat dengan Bandara Hang Nadim Batam dan Pelabuhan Internasional Batam Center. Kepadatan penduduk tersebut juga menyebabkan kebutuhan akan energi listrik menjadi sangat tinggi. Jika penduduk tidak bijak dalam menggunakan listrik, tentu saja akan Istilah data mining dan Knowledge Discovery in sangat mempengaruhi menipisnya persediaan energi Databases (KDD) sering kali digunakan secara lstrik di Kota Batam itu sendiri. Setiap penduduk wajib bergantian untuk menjelaskan proses penggalian mengetahui besarnya penggunaan listrik terlebih lagi informasi tersembunyi dalam suatu basis data yang dalam penggunaan listrik rumah tangga. Hal ini besar. Sebenarnya istilah tersebut memiliki konsep didasari atas perlunya kesadaran oleh penduduk dalam yang berbeda, tetapi berkaitan satu sama lain. Dan melakukan penghematan energi listrik. Penghematan salah satu tahapan dalam keseluruhan proses KDD listrik dapat dilakukan secara efektif apabila setiap adalah data mining [5].

rumah tangga sudah memiliki perilaku penghematan listrik [2].

Salah satu perusahaan penyedia energi listrik adalah Perusahaan Listrik Negara (PLN). Berdasarkan keputusan Menteri Negara Penanaman Modal dan Pembinaan BUMN, selaku Pemegang saham PT PLN (Persero) dalam surat No S-23/M-PM-PBMUN/2000 tanggal 23 Agustus 2000, pada tanggal 3 Oktober 2000, status PT PLN (Persero) Wilayah Khusus Batam berubah menjadi PT Pelayanan Listrik Nasional Batam (PT PLN Batam) dengan status sebagai anak perusahaan PT PLN (Persero), sebagai unit mandiri yang mengelola kelistrikan dari hulu sampai hilir dan pada Juni 2008 PT PLN Batam melakukan rebranding menjadi b'right PLN Batam.

\subsection{Data Mining}

Data Mining mengacu pada proses pencarian informasi yang tidak diketahui sebelumnya dari sekumpulan data besar [6]. Definisi lain Data Mining adalah serangkaian proses yang memperkerjakan satu atau lebih teknik pembelajaran komputer untuk menganalisis dan mengekstrak pengetahuan secara otomatis atau serangkaian proses untuk menggali nilai tambah dari suatu kumpulan data berupa pengetahuan yang selama ini tidak diketahui secara manual [7]. Menurut [8] Data mining adalah suatu istilah yang digunakan untuk menguraikan penemuan pengetahuan didalam database. Data mining adalah proses yang menggunakan teknik statistic, matematika, kecerdasan buatan, dan machine learning untuk mengekstraksi dan PT Pelayanan Listrik Nasional Batam atau PT PLN mengidentifikasi informasi yang bermanfaat dan Batam (b'right) yang berkantor pusat di Batam pengetahuan yang terkait dari berbagai database besar. Center adalah sebagai perusahaan utilitas penyedia layanan kebutuhan listrik kepada masyarakat. Untuk mengetahui penggunaan listrik rumah tangga diperlukan adanya prediksi. Prediksi penggunaan listrik rumah tangga dapat menggunakan teknik data mining. Data mining merupakan proses pengekstraksian informasi dari sekumpulan data yang sangat besar melalui penggunaan algoritma dan teknik penarikan dalam bidang statistik, pembelajaran mesin dan sistem manajemen basis data [3].

Jika dilihat dari defenisi mining yang berarti penambangan dari tumpukan data. Tumpukan data disini adalah data yang telah dikumpulkan sebelumnya. Tujuan dari penambangan data ini untuk memperoleh sejumlah informasi atau pengetahuan yang tersimpan didalam penambangan data dan dapat dimanfaatkan untuk kepentingan masyarakat maupun organisasi itu sendiri.

\subsection{Klasifikasi}

Teknik dalam melakukan prediksi dapat menggunakan Teknik klasifikasi adalah pendekatan sistematis untuk teknik klasifikasi pada Algoritma C4.5. Algoritma C4.5 membangun model klasifikasi dari kumpulan data memiliki banyak kelebihan diantaranya dapat masukan. Misalnya, teknik pohon keputusan, Bayesian menghasilkan model berupa pohon atau aturan yang (Naive Bayesian dan Bayesian Belief Networks), dapat dengan mudah diinterpretasikan. Pohon atau Jaringan Saraf Tiruan (Backpropagation), teknik yang aturan yang terbentuk dapat membantu dalam membaca berbasis konsep dari penambangan aturan-aturan asosiasi, dan teknik lain (K-Nearest Neighboor, 
algoritma genetik, teknik dengan pendekatan himpunan dari impuryt dan homogenity dari kumpulan data. Dari rough dan fuzzy). Klasifikasi merupakan teknik nilai Entropy tersebut kemudian dihitung nilai mengklasifikasikan data. Perbedaannya dengan metode information gain (IG) masing-masing atribut. Entropy clustering terletak pada data, dimana pada clustering $(S)$ merupakan jumlah bit yang diperkirakan variabel dependen tidak ada, sedangkan pada dibutuhkan untuk dapat mengekstrak suatu kelas (+ classification diharuskan ada variabel dependen [9].

\subsection{Pohon Keputusan (Decision Tree)}

Pohon keputusan menggunakan representasi struktur pohon (tree) di mana setiap node merepresentasikan atribut, cabangnya merepresentasikan nilai dari atribut dan daun merepresentasikan kelas. Node yang paling Untuk memilih atribut akar, didasarkan pada nilai gain atas dari pohon keputusan disebut sebagai root. Pohon tertinggi dari atribut-atribut yang ada. Untuk keputusan merupakan metode klasifikasi yang paling menghitung gain digunakan rumus seperti yang tertera populer digunakan. Selain karena pembangunannya dalam persamaan berikut.

relatif cepat, hasil dari model yang dibangun mudah untuk dipahami [7].

$$
\operatorname{Gain}(S, A)=\operatorname{Entropy}(S)-\sum_{i=1}^{n} \frac{|S i|}{|S|} * \operatorname{Entropy}(S i)
$$

Data dalam pohon keputusan biasanya dinyatakan Di mana: dalam bentuk tabel dengan atribut dan record. Atribut $S$ menyatakan suatu parameter yang disebut sebagai $A$ kriteria dalam pembentukan pohon. Manfaat utama dari $N$ penggunaan pohon keputusan adalah kemampuannya $|\mathrm{Si}|$ untuk mem-break down proses pengambilan keputusan $|S|$ yang kompleks menjadi lebih simpel sehingga pengambil keputusan akan lebih menginterpretasikan solusi dari permasalahan (Elmande, 2012). Misalkan untuk menentukan main tenis, kriteria yang diperhatikan adalah cuaca, angin, dan suhu. Salah satu atribut merupakan atribut yang menyatakan data solusi per item data yang disebut atribut hasil.

Pada pohon keputusan terdapat 3 jenis node, yaitu:

1. Root Node, merupakan node paling atas, pada node ini tidak ada input dan bisa tidak mempunyai output atau mempunyai output lebih dari satu.

2. Internal Node, merupakan node percabangan, pada node ini hanya terdapat satu input dan mempunyai output minimal dua.

3. Leaf node atau terminal node, merupakan node akhir, pada node ini hanya terdapat satu input dan tidak mempunyai output.

\subsection{Algoritma $\mathrm{C} 4.5$}

\section{: himpunan kasus}

: atribut

: jumlah partisi atribut $A$

: jumlah kasus pada partisi ke- $i$

: jumlah kasus dalam $S$

Sementara itu, perhitungan nilai entropi dapat dilihat pada persamaan 2 berikut.

$$
\operatorname{Entropy}(S)=\sum_{i=1}^{n}-p i * \log _{2} p i
$$

Di mana :

$$
\begin{array}{ll}
S & \text { : himpunan kasus } \\
A & : \text { fitur } \\
N & : \text { jumlah partisi } S \\
p i & \text { : proporsi dari } S i \text { terhadap } S
\end{array}
$$

Algoritma C4.5 dimulai dari proses memilih atribut dengan gain tertinggi sebagai akar pohon, kemudian membuat cabang untuk tiap-tiap nilai, lalu membagi kasus dalam cabang, setelah itu mengulangi proses untuk setiap cabang sampai semua kasus pada cabang memiliki kelas yang sama [11]. Secara umum algoritma C4.5 untuk membangun pohon keputusan adalah sebagai berikut :

a. Pilih atribut sebagai akar.

Algoritma C4.5 yaitu sebuah algoritma yang digunakan b. Buat cabang untuk tiap-tiap nilai. untuk membangun decision tree (pengambilan c. Bagi kasus dalam cabang. keputusan). Algoritma C.45 adalah salah satu algoritma d. Ulangi proses untuk setiap cabang sampai semua induksi pohon keputusan yaitu ID3 (Iterative Dichotomiser 3). ID3 dikembangkan oleh J. Ross Quinlan. Dalam prosedur algoritma ID3, input berupa 2.6. Tinjauan Umum Listrik Rumah Tangga sampel training, label training dan atribut. Algoritma C4.5 merupakan pengembangan dari ID3. Beberapa pengembangan yang dilakukan pada $\mathrm{C} 4.5$ adalah sebagai antara lain bisa mengatasi missing value, bisa mengatasi continu data, dan pruning [10].

Energi listrik adalah energi akhir yang dibutuhkan bagi peralatan listrik untuk menggerakkan motor, lampu penerangan, memanaskan, mendinginkan ataupun untuk menggerakkan kembali suatu peralatan mekanik untuk menghasilkan bentuk energi yang lain. Sebuah obyek yang diklasifikasikan dalam pohon harus [12]. Dalam rumah tangga, contoh pemakaian energi
dites nilai Entropy -nya. Entropy adalah ukuran dari listrik seperti mesin cuci, kipas angin, kulkas, setrika teori informasi yang dapat mengetahui karakteristik dan lain sebagainya. Pemakaian listrik ini juga 
dilatarbelakangi dari kemajuan teknolgi yang mempermudah manusia dalam melakukan pekerjaannya. Bisa kita bayangkan jika saat ini kita belum pernah sama sekali menyentuh fungsi dari listrik. Namun, dibalik penggunaannya yang sangat membantu, konsumsi energi listrik juga harus diseimbangkan. Pemerintah Indonesia saat ini sedang gencar-gencarnya mengkampanyekan program penghematan energi listrik, dimana pemakai listrik rumah tangga diharapkan mampu menghemat konsumsi listrik.

\subsection{Penelitian Terdahulu}

Adapun penelitian terdahulu yang mengacu pada pembahasan penelitian ini seperti terlihat pada tabel 1 berikut ini.

Tabel 1 Penelitian Terdahulu

\begin{tabular}{|c|c|}
\hline $\begin{array}{c}\text { Judul } \\
\text { Penelitian }\end{array}$ & \\
\hline $\begin{array}{l}\text { Implementasi } \\
\text { Metode } \\
\text { Klasifikasi } \\
\text { Nä̈ve Bayes } \\
\text { Dalam } \\
\text { Memprediksi } \\
\text { Besarnya } \\
\text { Penggunaan } \\
\text { Listrik Rumah } \\
\text { Tangga } \\
\text { [3] }\end{array}$ & $\begin{array}{l}\text { Metode Naive Bayes } \\
\text { memanfaatkan data training untuk } \\
\text { menghasilkan probabilitas setiap } \\
\text { kriteria untuk class yang berbeda, } \\
\text { mengklasifikasikan } 47 \text { data dari } \\
60 \text { data yang diuji. Sehingga } \\
\text { metode Naive Bayes berhasil } \\
\text { memprediksi } \\
\text { penggunaan listrik rumah tangga } \\
\text { dengan persentase keakuratan } \\
\text { sebesar } 78,3333 \% \text {. }\end{array}$ \\
\hline $\begin{array}{l}\text { Data Mining } \\
\text { Peramalan } \\
\text { Konsumsi } \\
\text { Listrik dengan } \\
\text { Pendekatan } \\
\text { Cluster Time } \\
\text { Series sebagai } \\
\text { Preprocessing } \\
{[13]}\end{array}$ & $\begin{array}{l}\text { Hasil yang diperoleh adalah } \\
\text { dihasilkan sebanyak tujuh cluster } \\
\text { dengan anggota cluster terbanyak } \\
\text { pada cluster ke empat yakni } \\
\text { sebanyak } 120 \text { client. Selanjutnya } \\
\text { model peramalan dengan } \\
\text { menggunakan ANN lebih baik } \\
\text { dibandingkan ARIMA. Diperoleh } \\
\text { sebanyak } 259 \text { dari } 348 \text { client yang } \\
\text { menyatakan bahwa permodelan } \\
\text { dengan menggunakan ANN lebih } \\
\text { baik dibandingkan ARIMA. }\end{array}$ \\
\hline $\begin{array}{l}\text { Penentuan } \\
\text { Daya Listrik } \\
\text { Rumah } \\
\text { Tangga } \\
\text { Menggunakan } \\
\text { Metode } \\
\text { Decision Tree } \\
{[14]}\end{array}$ & $\begin{array}{l}\text { Penggunaan algoritma dari } \\
\text { metode decision tree baik } \\
\text { algoritma ID3 maupun C4.5 dapat } \\
\text { menentukan daya listrik rumah } \\
\text { tangga. Hasil akurasi kedua } \\
\text { algoritma menggunakan confusion } \\
\text { matrix dengan data sejumlah } 300 \\
\text { yang terdiri dari } 150 \text { data training } \\
\text { dan } 150 \text { data testing menunjukan } \\
\text { algoritma C4.5 dengan akurasi } 88 \\
\% \text { lebih akurat daripada algoritma } \\
\text { ID3 yang memiliki akurasi } 62 \% \text {. }\end{array}$ \\
\hline
\end{tabular}

\section{Metodologi Penelitian}

Metodologi merupakan langkah-langkah yang akan dilakukan pada penelitian ini. Langkah - langkah tersebut digambarkan pada gambar 1 .

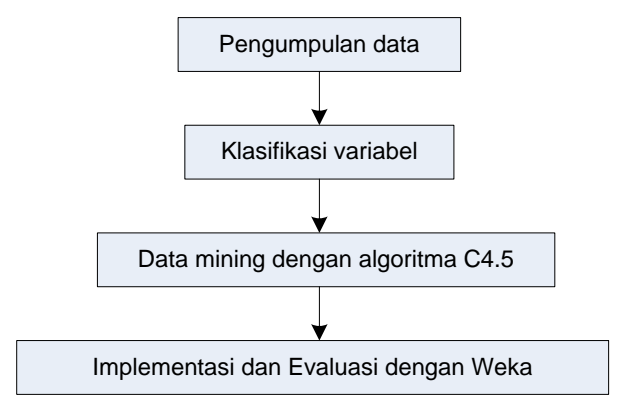

Gambar 1 Metodologi Penelitian

Uraian dari gambar 1 adalah langkah awal dari penelitian ini yaitu peneliti terlebih dahulu melakukan pengumpulan data. Dari data yang dikumpul dilakukan pengklasifikasian pada variabel agar mudah diolah. Kemudian,dilakukan analisa dengan teknik algoritma C4.5 yang akan membentuk pohon keputusan. Dari hasil pohon keputusan tersebut akan dibandingkan dengan hasil pengolahan menggunakan Weka.

\section{Hasil dan Pembahasan}

\subsection{Klasifikasi Data}

Data yang telah dikumpulkan dalam kuisioner harus diklasifikasikan untuk mempermudah dalam perhitungan. Adapun pengklasifikasian data pada variabel penelitian ini ada pada tabel $2-6$.

Tabel 2 Klasifikasi Pendidikan

\begin{tabular}{cc}
\hline Pendidikan & Klasifikasi \\
\hline SMA/K & SMA \\
Sarjana & S \\
\hline
\end{tabular}

Tabel 3 Klasifikasi Total Barang Elektronik

\begin{tabular}{cc}
\hline Total Barang Elektronik & Klasifikasi \\
\hline$<11$ & $\mathrm{~S}$ \\
$>11$ & $\mathrm{~B}$ \\
\hline
\end{tabular}

Tabel 4 Klasifikasi Jumlah ANggota Keluarga

\begin{tabular}{cc}
\hline Jumlah Anggota Keluarga & Klasifikasi \\
\hline$<3$ & $\mathrm{~S}$ \\
$>3$ & $\mathrm{~B}$ \\
\hline
\end{tabular}

Tabel 5 Klasifikasi Lama Waktu di Rumah

\begin{tabular}{cc}
\hline Lama Waktu di Rumah & Klasifikasi \\
\hline$<12$ & $\mathrm{~S}$ \\
$>12$ & $\mathrm{~L}$ \\
\hline
\end{tabular}

Tabel 6 Klasifikasi Luas Bangunan Rumah

\begin{tabular}{cc}
\hline Luas Bangunan Rumah & Klasifikasi \\
\hline Type 32 & $\mathrm{K}$ \\
Type 34 & $\mathrm{S}$ \\
Type 36 & $\mathrm{L}$ \\
\hline
\end{tabular}




\subsection{Hasil Penelitian}

Dari data yang telah diklasifikasikan maka dilakukan perhitungan algoritma C4.5 untuk mencari entropy tertinggi dari setiap atribut. Hasil perhitungan node 1 dapat dilihat pada tabel 7.

Tabel 7 Perhitungan Node 1

\begin{tabular}{|c|c|c|c|c|c|c|}
\hline Nede & $\begin{array}{c}\text { Jamlab } \\
\text { Kasus(S) }\end{array}$ & & Ya (SI) & $\begin{array}{l}\text { Trdak } \\
\text { (S2) }\end{array}$ & Entrepy & Gai \\
\hline 1 Total & & 50 & 35 & 15 & 0.881290899 & \\
\hline \multirow[t]{2}{*}{ Pendidikan } & SMA & 23 & 17 & 6 & 0.828055725 & 0.004505515 \\
\hline & $\mathbf{s}$ & 27 & 18 & 9 & 0918295834 & \\
\hline Totel Barang & $\mathbf{B}$ & 34 & 26 & 8 & 0.787126586 & 0.02966101 \\
\hline Flektronik & $\mathbf{s}$ & 16 & 9 & 7 & 0.988699408 & \\
\hline
\end{tabular}

\begin{tabular}{lrrrrrr}
$\begin{array}{lrrrrr}\text { Jumlah Anggota } \\
\text { Keluarga }\end{array}$ & B & 27 & 25 & 2 & 0380946586 & 0.221241189 \\
& S & 23 & 10 & 13 & 0.987692509 & \\
& & & & & & \\
Lama Walktu Di & L & 46 & 34 & 12 & 0.828055725 & 0.054577382 \\
Rmmah & S & 4 & 1 & 3 & 0.811278124 & \\
& & & & & & \\
Luas Bangunan & L & 33 & 26 & 7 & 0.745517843 & $\mathbf{0 . 0 7 4 4 2 5 3 5 6}$ \\
Rmmah & S & 13 & 8 & 5 & 0.961236605 & \\
& K & 4 & 1 & 3 & 0.811278124 & \\
\hline
\end{tabular}

Padatabel 7 didapat entropy tertinggi ada pada variabel Jumlah Anggota Keluarga dimana Jumlah Anggota Keluarga Banyak maka penggunaan listrik Tinggi, untuk Jumlah Anggota Keluarga Sedikit perlu dilakukan lagi perhitungan untuk mencari akarnya. Pohon keputusan yang terbentuk dari perhitungan Node 1 seperti pada gambar 2 .

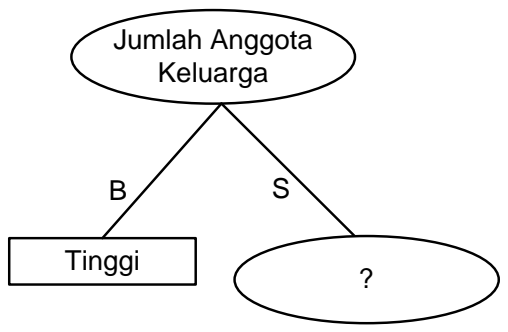

Gambar 2 Pohon Keputusan Node 1

perhitungan selanjutnya yaitu menyortir data Jumlah Anggota Sedikit dengan perhitungan node 1.1 yang terbentuk seperti pada gambar 4 . dengan hasil perhitungan seperti pada Tabel 8.

Tabel 8 Perhitungan Node 1.1

\begin{tabular}{|c|c|c|c|c|c|c|}
\hline Nede & \multicolumn{2}{|c|}{ Jnblh Kasus(S) } & \multirow{2}{*}{$\begin{array}{r}\begin{array}{c}\text { Ya } \\
\text { (SI) }\end{array} \\
10\end{array}$} & $\begin{array}{c}\text { Tidak } \\
\text { (S2) }\end{array}$ & \multirow{2}{*}{$\begin{array}{c}\text { Entropy } \\
0.987692509\end{array}$} & \multirow[t]{2}{*}{ Gai } \\
\hline 1.1 Jumlah Anggota & duarga $S$ & 23 & & 13 & & \\
\hline \multirow[t]{2}{*}{ Pendidikan } & SMA & 10 & 5 & 5 & 1 & 0.009602254 \\
\hline & $\mathbf{s}$ & 13 & 5 & 8 & 0961236605 & \\
\hline \multirow[t]{2}{*}{ Total Barang Eled } & $\mathbf{B}$ & 9 & 3 & 6 & 0.918295834 & 0.019663704 \\
\hline & $\mathbf{s}$ & 14 & 7 & 7 & 1 & \\
\hline \multirow[t]{2}{*}{ Lama Waktu Di I } & $\mathbf{L}$ & 19 & 9 & 10 & 0998000884 & 0.022165148 \\
\hline & $\mathbf{s}$ & 4 & $\mathbf{1}$ & 3 & 0.811278124 & \\
\hline \multirow[t]{3}{*}{ Luas Bangunan $R$} & $\mathbf{L}$ & 17 & 10 & 7 & 0977417818 & 0.265253252 \\
\hline & $\mathbf{s}$ & 4 & $\mathbf{0}$ & 4 & 0 & \\
\hline & $\mathbf{K}$ & 2 & $\mathbf{0}$ & 2 & 0 & \\
\hline
\end{tabular}

Didapatkan lagi untuk entropy tertinggi ada pada variabel Luas Bangunan Rumah dengan kategori Luas Bangunan Rumah Sedang maka penggunaan listrik Rendah. Luas Bangunan Rumah Kecil juga penggunaan listrik Rendah. Namun, untuk Luas Bangunan Rumah Luas perlu dicari lagi atribut selanjutnya. Pohon keputusan yang terbentuk dapat ilihat pada gambar 3 .

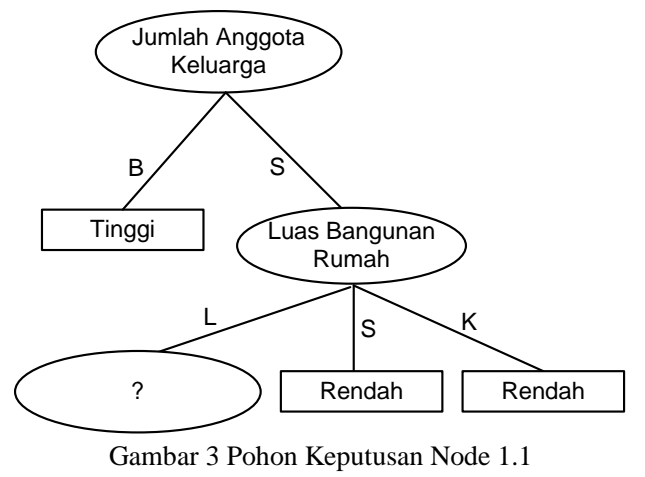

Selanjutnya disortir data Luas Bangunan Rumah dengan kategori Luas. Adapun hasil perhitungan Node 1.2 dapat dilihat pada tabel 9.

Tabel 9 Perhitungan Node 1.2

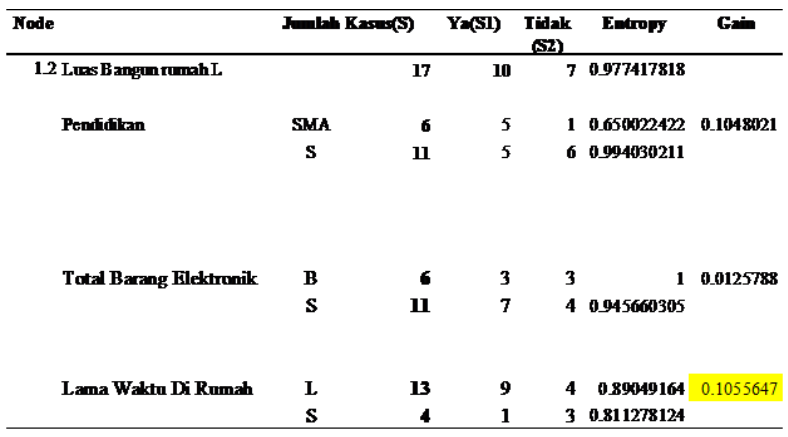

Dari tabel 9 dilihat entropy tertinggi ada pada variabel Lama Waktu di Rumah, dimana jika Lama maka penggunaan listrik Tinggi dan jika Sebentar maka

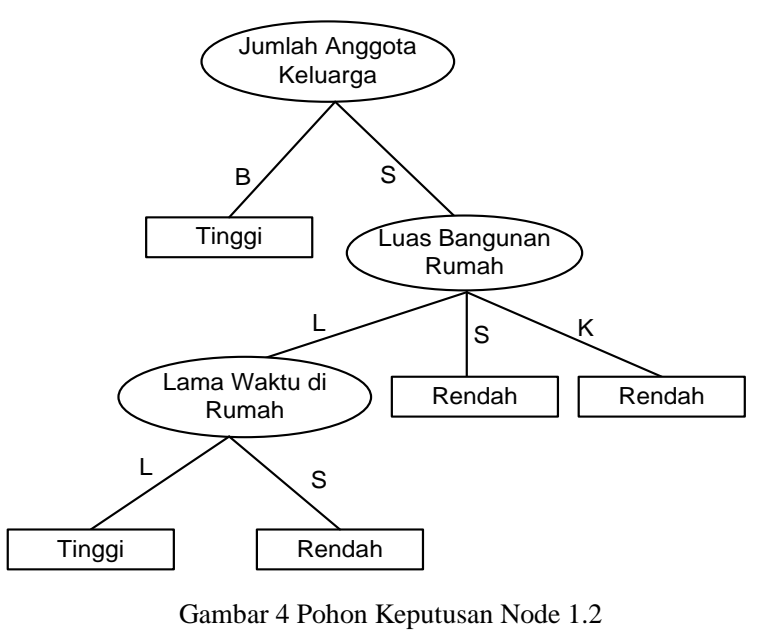


Hasil pengujian yang dilakukan menggunakan software 5. Kesimpulan

Weka dengan hasil pohon keputusan seperti gambar 5.

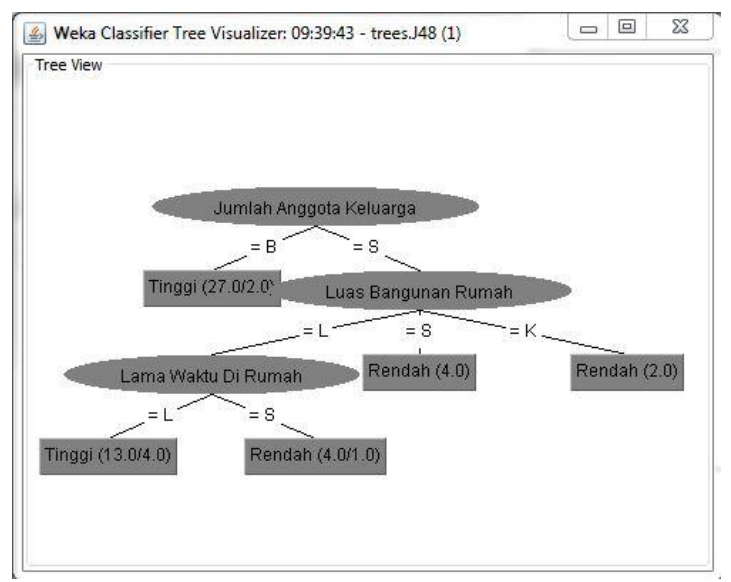

Gambar 5 Hasil Pengujian Weka

\subsection{Pembahasan}

Pada pencarian entropy secara manual didapat rule dari hasil pohon keputusan sebagai berikut :

1. Jika jumlah anggota keluarga banyak maka penggunaan listri tinggi.

2. Jika jumlah anggota keluarga sedikit dan luas bangunan rumah sedang, maka penggunaan listrik rendah.

3. Jika jumlah anggota keluarga sedikit dan luas bangunan rumah kecil, maka penggunaan listrik rendah.

4. Jika jumlah anggota keluarga sedikit dan luas bangunan rumah luas dan lama waktu di rumah lama, maka penggunaan listrik tinggi.

5. Jika jumlah anggota keluarga sedikit dan luas bangunan rumah luas dan lama waktu di rumah sebentar, maka penggunaan listrik rendah.

Kemudian kita bandingkan dengan hasil rule yang terbentuk dari pengujian Weka yaitu :

1. Jika jumlah anggota keluarga banyak maka penggunaan listri tinggi.

2. Jika jumlah anggota keluarga sedikit dan luas bangunan rumah sedang, maka penggunaan listrik rendah.

3. Jika jumlah anggota keluarga sedikit dan luas bangunan rumah kecil, maka penggunaan listrik rendah.

4. Jika jumlah anggota keluarga sedikit dan luas bangunan rumah luas dan lama waktu di rumah lama, maka penggunaan listrik tinggi.

5. Jika jumlah anggota keluarga sedikit dan luas bangunan rumah luas dan lama waktu di rumah sebentar, maka penggunaan listrik rendah.

Maka disimpulkan dari perhitungan manual dan pengujian dengan Weka rule yang dihasilkan sama dan pengujian ini sangat baik.

\subsection{Simpulan}

Simpulan dari penelitian ini adalah sebagai berikut :

1. Hasil perhitungan dengan menggunakan Algoritma C4.5 dapat melakuakan prediksi besarnya penggunaan listrik di Kota Batam dengan memperhatikan nilai gain (penguatan) tertinggi dari lima atribut yang digunakan yaitu pendidikan, jumlah anggota keluarga, total barang elektronik, jumlah pemakai, lama waktu di rumah dan luas bangunan rumah.

2. Hasil perhitungan dengan Algoritma C4.5 dengan metode pohon keputusan dapat memberikan informasi rule prediksi untuk menggambarkan proses yang terkait dengan prediksi besarnya penggunaan listrik rumah tangga. Dimana, variabel jumlah anggota keluarga, luas bangunan rumah , dan lama waktu di rumah menjadi variabel penting dalam membentuk pohon keputusan.

3. Hasil pengujian yang dilakukan menggunakan Weka didapatkan rule yang dihasilkan dengan menggunakan perhitungan manual adalah sama. Sehingga pengujian dengan Weka sangat baik.

\subsection{Saran}

1. Perlu dilakukan penambahan variabel karena akan sangat mempengaruhi dari hasil prediksi untuk penelitian besarnya penggunaan listrik rumah tangga.

2. Perlu dilakukan penelitian untuk membandingkan hasil menggunaan algoritma lain guna mendapatkan hasil prediksi yang lebih baik lagi.

\section{Ucapan Terima Kasih}

Terima kasih kepada DIKTI atas pendanaan penelitian ini sebagai Penelitian Dosen Pemua (PDP) Lampiran Surat Nomor : 0045/E3/LL/2018

\section{Daftar Rujukan}

A. Rahman and K. Nanggalo, "Prakiraan Dan Analisa Kebutuhan Energi Listrik Provinsi Sumatera Barat Hingga Tahun 2024 Dengan Metode Analisis Regresi Linear Berganda," J. Tek. Elektro ITP, vol. 4, no. 2, 2015.

[2] L. N. Y. Sari, Moh. Djemdjem Djamaludin, and Anggi Mayang, "Analisis Sikapdan Perilaku Penghemaan Listrik Pada Sektor Rumah Tangga," vol. 4, no. 1, pp. 82-90, 2011.

[3] A. Saleh, "Implementasi Metode Klasifikasi Naïve Bayes Dalam Memprediksi Besarnya Penggunaan Listrik Rumah Tangga," Citec J., vol. 2, pp. 207-217, 2015.

[4] B. R. Siburian, "Aplikasi Data Mining Untuk Menampilkan Tingkat Kelulusan Mahasiswa Dengan Algoritma ApriorI," Pelita Inform. Budi Darma, vol. VII, pp. 56-61, 2014.

[5] M. Le Cam, A. Daoud, and R. Zmeureanu, "Forecasting electric demand of supply fan using data mining techniques," Energy, vol. 101, pp. 541-557, 2016.

[6] I. H. Selvia Lorena Br Ginting, Wendi Zarman, "Analisis Dan Penerapan Algoritma C4.5 Dalam Data Mining Untuk Memprediksi Masa Studi Mahasiswa Berdasarkan Data Nilai Akademik," no. November, 2014. 
Yulia, Nurul Azwanti

Jurnal RESTI (Rekayasa Sistem dan Teknologi Informasi) Vol. 2 No. 2 (2018) 584 - 590

[7] A. Sijabat, "Penerapan Data Mining Untuk Pengolahan Data Siswa Dengan Menggunakan Metode Decision Tree ( Studi Kasus : Yayasan Perguruan,”vol. V,pp. 7-12, 2015.

[8] Kusrini and Luthfi, Algoritma Data Mining. Yogyakarta: Penerbit Andi, 2009.

[9] D. H. Kamagi and S. Hansun, "Implementasi Data Mining dengan Algoritma C4 . 5 untuk Memprediksi Tingkat [ Kelulusan Mahasiswa," vol. VI, no. 1, pp. 15-20, 2014

[10] S. Faradillah, "Implementasi Data Mining Untuk Pengenalan Karakteristik Transaksi Customer," pp. 63-70, 2013.

[11] Y. A. Fiandra, S. Defit, and Yuhandri, "Penerapan Algoritma C4.5 untuk Klasifikasi Data Rekam Medis berdasarkan International Classification Diseases (ICD-10)," J. RESTI
(Rekayasa Sist. dan Teknol. Informasi), vol. 1, no. 2, pp. 8289, 2017.

12] W. Widjayanti, "Profil Konsumsi Energi Listrik Pada Hunian Rumah Tinggal Studi Kasus Rumah Desain Minimalis Ditinjau Dari Aspek Pencahayaan Buatan," Enclosure, vol. 6, no. 2, pp. 97-106, 2007.

[13] M. A. A. Riyadi and K. Fithriasari, "Data Mining Peramalan Konsumsi Listrik dengan Pendekatan Cluster Time Series sebagai Preprocessing," vol. 5, no. 1, 2016.

[14] Y. P. Tanjung, S. Sentinuwo, and A. Jacobus, "Penentuan Daya Listrik Rumah Tangga Menggunakan Metode Decision Tree." 